\title{
Importance of physical health and health- behaviors in adolescence for risk of dropout from secondary education in young adulthood: an 8-year prospective study
}

Erla Svansdottir ${ }^{1,4^{*}}$, Sigurbjorn A. Arngrimsson ${ }^{1,2}$, Thorarinn Sveinsson ${ }^{3}$ and Erlingur Johannsson ${ }^{1,2}$

\begin{abstract}
Background: Education and health constitute two interlinked assets that are highly important to individuals. In Iceland, prevalence of dropout from secondary education poses a considerable problem. This 8-year prospective study assesses to what extent poor physical health and negative health-behaviors of Icelandic adolescents predict increased odds of dropout from secondary education.

Methods: The sample included $n=201$ Icelandic children who participated at age 15 (baseline) and again at age 23 (follow-up). Data included objective measurements of physical health and questionnaires assessing health-behaviors, education status, parental education, neighborhood characteristics, self-esteem, and depression. Independent t-tests and chi-square were used to assess differences in physical health and health-behaviors at follow-up stratified by education status. Ordinal regression models were conducted to assess whether physical health and health-behaviors at age 15 predicted increased odds of dropout from secondary education at age 23, independent of gender, parental education and psychological factors.
\end{abstract}

Results: At age $23,78 \%$ of girls and $71 \%$ of boys had completed a secondary education. Completion of a secondary education was associated with significant health benefits, especially among women. Women without a secondary education had lower fitness, more somatic complaints, higher diastolic blood pressure, less sports participation, and poorer sleep, whilst men without a secondary education watched more television. In logistic regression models somatic complaints during adolescence were associated with 1.09

( $95 \%$ Cl: 1.02-1.18) higher odds of dropout from secondary education in young adulthood, independent of covariates. Health-behaviors associated with higher dropout odds included smoking (3.67, 95 \% Cl: 1.50-9.00), alcohol drinking (2.57, $95 \%$ Cl: 1.15-5.75), and time spent watching television (1.27, $95 \%$ Cl:1.03-1.56), which were independent of most covariates. Finally, mother's higher education was strongly associated with significantly lower dropout odds (OR 0.54, $95 \%$ Cl: 0.34-0.88) independent of father's education and psychological factors, whilst high self-esteem was independently associated with lower dropout odds (OR 0.91, 95 \% Cl: 0.85-0.98).

Conclusions: Completion of a secondary education yields substantial physical health benefits for young women, but not for men. Importantly, somatic complaints and negative health-behaviors among adolescent boys and girls adversely impact their educational outcomes later in life, and may have widespread consequences for their future prospects.

Keywords: Adolescence, Health Inequalities, Education, Gender, Health-behaviors

\footnotetext{
* Correspondence: erlas@hi.is

${ }^{1}$ School of Education, University of Iceland, Stakkahlíð, 105 Reykjavík, Iceland

${ }^{4}$ Landspitali-University Hospital, Eiríksgötu 5, 101, Reykjavík, Iceland

Full list of author information is available at the end of the article
}

C Biomed Central (c) 2015 Svansdottir et al. Open Access This article is distributed under the terms of the Creative Commons Attribution 4.0 International License (http://creativecommons.org/licenses/by/4.0/), which permits unrestricted use, distribution, and reproduction in any medium, provided you give appropriate credit to the original author(s) and the source, provide a link to the Creative Commons license, and indicate if changes were made. The Creative Commons Public Domain Dedication waiver (http://creativecommons.org/publicdomain/zero/1.0/) applies to the data made available in this article, unless otherwise stated. 


\section{Background}

Education is an important asset for individuals in today's society. Completion of secondary education provides young adults with the technical and vocational skills needed to secure good jobs and/or the rights to progress to university [1]. Hence, not completing a secondary education can lead to considerable costs to individuals, through lower earnings or unemployment, and the society, via lower tax revenue and higher spending on public assistance [2].

Education is considered of high importance in Iceland, as all children and young adults are given an equal right to education, free of charge, in both compulsory and upper secondary school. In the Icelandic Education System students attend compulsory school from ages 6-15, whilst secondary education is typically planned from ages 16-19 [3]. However, dropout from secondary education in the Icelandic setting is a considerable problem, with a prevalence of $30 \%$, and only $45 \%$ of students graduate on time [4]. In light of this, the Ministry of Education, Science and Culture has put forward the goal to increase completion of secondary education in Iceland on time to $60 \%$ by 2018 [5].

One way to prevent dropout from secondary education could be through health promotion, focusing on students' physical and mental health within secondary schools. An inquiry made by the Ministry of Education, Science and Culture among Icelandic secondary schools in 2013 has noted that $17 \%$ of dropout students cited health-related reasons for their dropout, including physical and mental health problems (with other main reasons comprising for example failed attendance ( $25 \%)$, started working (11\%), transferred to another school (12\%), lack of interest (4\%), and financial difficulties (3\%) [6]. Large longitudinal studies have likewise linked low general health status, obesity, and health problems with higher odds of dropout from secondary education $[7,8]$, indicating that poor health may be an influential factor for lower educational attainment among youths.

Importantly, a report from the World Health Organization (WHO) has specifically criticized how little emphasis western countries have given the influence of health and health-behaviors of children and adolescents on their educational attainment. In the report they question the one directionality in research on this topic, that is why the vast majority of studies have only investigated how lower educational attainment is associated with poorer health (i.e. the educational gradient in health [9]), but not how health factors may affect educational attainment [10]. Notably, very few studies have investigated this topic in Europe [11], and the ones that have are moreover limited to a certain extent as they have mostly been based on infant or self-report health data [12], or short-term academic outcomes [13]. Data regarding how psychological factors affect this association are also scarce, particularly concerning depression [10]. Lastly, few studies have adjusted for the possible confounding effects of parental education, an important index of socioeconomic status [13, 14], and neighborhood characteristics. Although Iceland contains a largely homogeneous population, with a low unemployment rate and an education and healthcare system similar to the other Nordic countries [15] there is some evidence that socio-economic and neighborhood differences in health and well-being are present within the country. Recent findings have for instance reported that socioeconomic inequalities are largest in Iceland of all the Nordic countries [16], and linked certain neighborhood characteristics with more substance abuse among adolescents [17]. Importantly, these factors might influence risk of dropout from secondary school as well, which would directly conflict with the fundamental principle of the Icelandic Education System concerning equal rights for acquiring an education regardless of gender, social status, cultural background, or residential location [18].

Thus, the objective of the current study is to investigate prospectively the relationship between health and education among Icelandic adolescents, with a specific focus on how physical health and healthbehaviors during adolescence influence educational attainment in young adulthood. More specifically, the aims are: 1) to evaluate differences in the physical health, health-behaviors, and psychological factors of young adults who have or have not completed a secondary education; 2) to examine how physical health and negative health-behaviors of adolescents affect their odds of dropout from secondary education; and 3) to examine if such associations remain after controlling for parental education and psychological factors. We hypothesize that young adults who have completed a secondary education will report better physical health, more positive health-behaviors, and a better standing on psychological factors, and that poorer standing on physical health and healthbehaviors will be linked with a higher risk of dropout from secondary education, independent of covariates.

\section{Methods}

\section{Participants}

This study is based on a previous sample of $N=385$ children (195 boys, 190 girls) born in 1988 from 18 schools selected based on the geographical distribution in Iceland, with $60 \%$ of participants from the metropolitan Reykjavik-area and $40 \%$ from the north-east of Iceland. This sample constitutes $10 \%$ of the overall population of Icelandic citizens at this age group. These students were originally approached for participation in 2003 
when they attended 10th grade (age 15) of primary school, and a written informed consent was obtained from parents and participants. For the current study, a follow-up was conducted eight years later when participants were 23-years old. At the follow - up, $n=333$ (86 \%) of the original sample was successfully located and invited to partake in the study. The $n=52$ individuals lost at follow - up were subjects who were not found in the National Registry and had most likely moved abroad with their parents or for studies. The scheme for participation in the follow-up study is displayed in detail in Fig. 1. The Icelandic Bioethics Committee approved the study and it was conducted according to the ethical tenets of the Declaration of Helsinki. The study design and measurements were conducted in line with the protocol of the European Youth Heart Study [19].

\section{Measures}

Demographics: socio-economic status and neighborhood characteristics

Information regarding parental education (what level of education participants' mothers and fathers had completed (i.e. primary education, vocational education, matriculation examination, university degree)) was collected from participants at follow-up, and used as a proxy measure for socio- economic status. Participant's occupation status and child-rearing responsibilities (whether they had children) were assessed with self-report at follow-up. Neighborhood characteristics of participants were defined by the local-area their respective schools resided in. These were categorized into two areas: a) metropolis (Reykjavik capital area (six schools), and urban/rural (12 schools from smaller towns and rural areas).

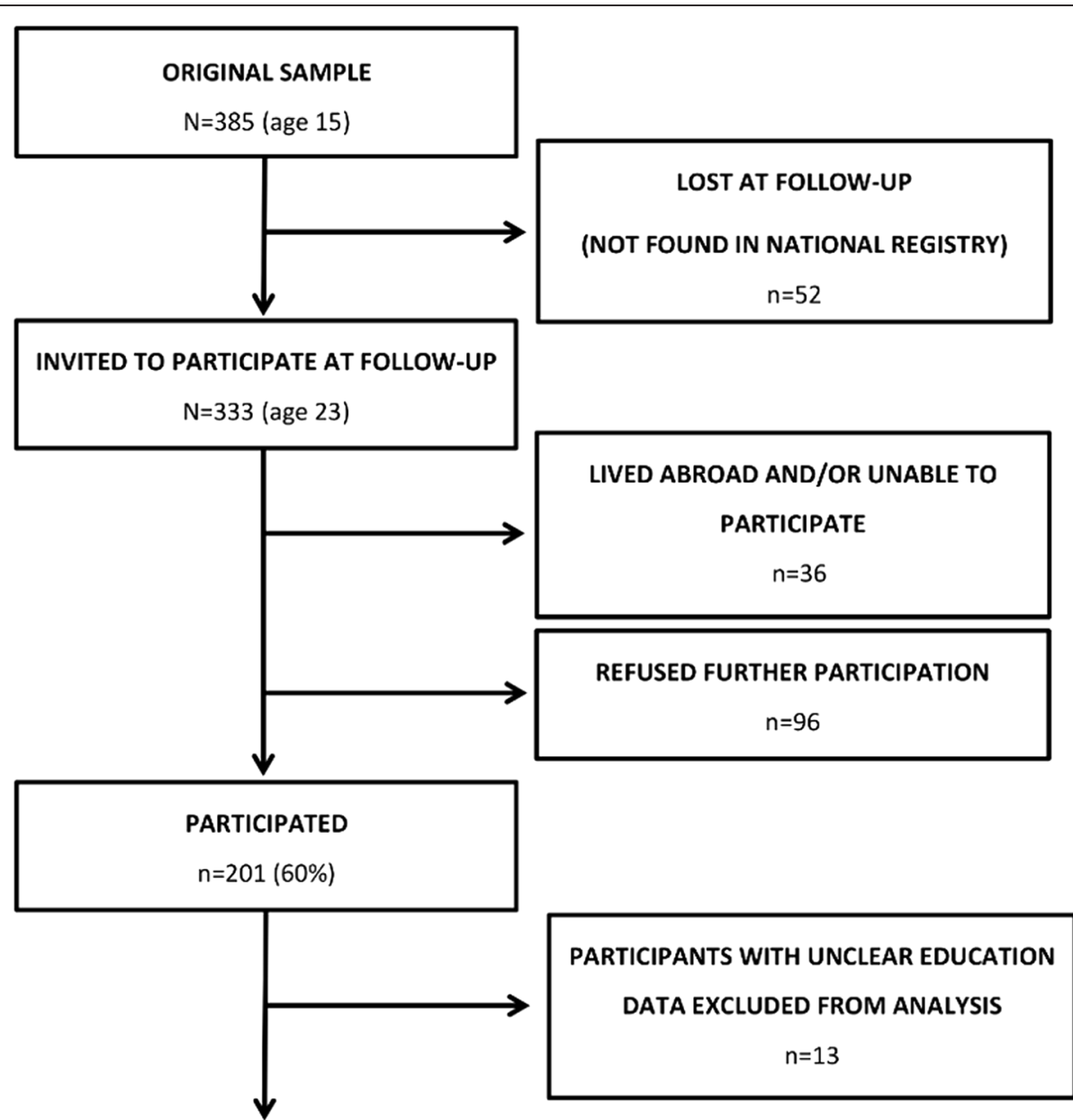

INCLUDED IN MAIN ANALYSIS

$\mathrm{n}=188$

Fig. 1 Overview of participation and dropout from the original and follow-up study 


\section{Physical health}

Objective measures of physical health were conducted at both baseline and follow-up. Of note, due to limited funding resources at baseline, objective measures of fitness (with a bicycle ergometer) and physical activity (with accelerometers) were only conducted among half of the participant sample at baseline. Thus, half of participants from each student class were invited to undergo fitness and physical activity measures at baseline. Conversely, these two measures were conducted among all participants at follow-up. Fitness was assessed with performance on a maximal graded bicycle ergometer (Monark 839E) test [20, 21]. A description of the test was given, and the importance of maximal effort was stressed, but participants were also told they could stop cycling at any time. The test has been validated in adolescents [20]. Physical activity was objectively measured with Actigraph activity monitors (model GT3X). Participants carried activity monitors secured by waist belt at their right hip for six consecutive days including both weekend days. These monitors have been validated in youths [22, 23], and the measurement used was counts per minute. Standing height was measured with a transportable stadiometer to the nearest millimeter, and body weight was determined to the nearest $0.1 \mathrm{~kg}$ on a scale. Body Mass Index (BMI) was calculated as body mass (kg) divided by height (m) squared. Waistcircumference and skinfold thickness were assessed using standardized procedures. Blood pressure was measured at follow-up using a validated, semi-automated device (ADC Advantage) after participants had rested for ten minutes. Measures were taken over the brachial artery three times. The average of the last two recordings was used. The Somatization subscale of the Symptom Checklist 90 (SCL-90) [24] was used to assess occurrences of subjective and psychological health complaints (e.g. stomach ache and headache) in the past seven days. The subscale contains eight items scored on a five-point Likert scale.

\section{Health - behaviors}

Health-behavior measures included the following at baseline and follow-up: a) smoking in the past 30 days (no, yes); b) alcohol consumption in the past 30 days (no, yes); c) number of hours spent watching television each weekday (almost never, 30-60 $\mathrm{min}, \approx 1 h, \approx 2 h, \approx 3 h$, $\approx 4 h, \approx 5 h, \geq 6 h$ ); and d) how often participants engaged in moderate/vigorous physical activity (d.1) or sports (d.2) (never/rarely, 1-3 times a week, $\geq 4$ times a week). The following health-behaviors were only assessed at follow-up: a) "How many hours do you spend sleeping on weekdays?" ( $\leq 7 \mathrm{~h}$ per night, $\geq 8 \mathrm{~h}$ ); and b) "How often do you get enough sleep?" (very seldom, about half of the time, most nights, sleep too much). Prior to analyses, categories for b) were combined into a binary variable indicating "I don't get enough sleep" (very seldom/half of the time) versus "I get enough sleep" (most nights/sleep too much).

\section{Psychological factors}

Measures of psychological factors included self-esteem and depression, which were measured at baseline and follow-up, and life satisfaction and social support, which were assessed at follow-up only. Self-esteem was assessed using the Rosenberg Self - Esteem Scale [25]. The scale includes ten statements with four response options. Total scores range from $0-30$ with higher scores reflecting greater self-esteem. The psychometric properties of the Icelandic version have been deemed sufficient [26]. The Depression subscale of the SCL-90 [24] was used to assess symptoms of depression in the preceding week. The ten-item subscale is scored on a five-point Likert scale asking about feelings the last seven days. Life satisfaction was assessed with Dieners' Satisfaction with Life Scale [27], a five-item scale measuring global cognitive judgment of one's life satisfaction. Participants indicate on a seven-point scale how much they agree or disagree with each item. Finally, the Multidimensional Scale of Perceived Social Support [28] was used to measure social support. Psychometric evaluations have verified the reliability and validity of the scale among adolescents [29].

\section{Education completion}

Participants reported at follow-up what education they had completed (i.e. primary education, vocational education, matriculation examination, university education). In the Icelandic education system students usually complete elementary school at age 15-16 and vocational/matriculation examination at age 19-20 [3]. Dropout from secondary education was defined by only having an elementary education by age 23 , whilst having completed a vocational-, matriculation-, and/or university education was categorized as "has completed a secondary education". Participants with "other education" were excluded from analyses due to lack of information regarding their education ( $n=7$ girls and $n=6$ boys). No differences were noted in living location, gender, parental education status, nor in any measure of physical health at baseline or follow-up between participants and excluded subjects, except that those excluded from analyses had lower BMI at baseline $(M=20.9$ (SD 2.9) vs. $\mathrm{M}=19.1$ (SD 1.6), $\mathrm{p}=0.029)$ and follow-up $(\mathrm{M}=24.4$ (SD 3.9) vs. 21.7 (SD 2.8), $p=0.013$ ), and a lower waistcircumference $(M=78.5 \mathrm{~cm}(\mathrm{SD} 10.8)$ vs. $\mathrm{M}=71.7 \mathrm{~cm}$ (SD 8.4), $p=0.025)$ at follow-up. 


\section{Statistical analyses}

Independent t-tests, chi-square, and tau-c rank correlations were used to a) assess gender differences in demographics and covariates at baseline (i.e. parental education, neighborhood characteristics, and psychological factors); and b) examine differences in physical health measures, health-behaviors and socio-demographics at follow-up by educational status, across the whole sample and stratified by gender (i.e. among girls and boys separately).

A logistic regression was conducted to assess the influence of physical health, health-behaviors and covariates at baseline on odds of dropout from secondary education. Three different hierarchal models were executed in the whole sample, using the stepwise method and controlling for different covariates per model. In all models a single independent variable (one physical health or health-behavior measure) was inserted at the 1st step and gender at the 2nd step. The models differed however at the 3rd step, with Model 1 containing no further adjustment, while Model 2 was adjusted for mother's and father's education status and neighborhood characteristics; and Model 3 adjusted for baseline self-esteem and depression. These models were subsequently repeated for each covariate (i.e. gender, mother's higher education, father's higher education, neighborhood characteristics, self-esteem, and depression) to assess their independent effects. In these models, each covariate was inserted at the 1 st step, with steps $2-3$ run as described above except that the relevant covariate was excluded from later steps.

\section{Results}

Demographics are presented in Table 1. Participants education status differed by gender $($ Tau-c $(N=201)=$ $-0.19, p=0.01)$. More boys had completed vocational studies $\left(\chi^{2}(1,201)=9.333, p=0.002\right)$, while more girls had completed a matriculation examination $\left(\chi^{2}(1,201)=\right.$ 9.158, $p=0.002)$. Using the aforementioned definition of secondary education, $78 \%$ of girls $(n=72)$ and $71 \%$ of boys $(n=78)$ had completed a secondary education by age 23.

\section{Health differences in young adulthood by education status}

Differences in physical health, health-behaviors, and psychological factors at follow-up by education status are presented in Table 2. Across the whole sample, individuals who had completed a secondary education reported higher life satisfaction, less somatic complaints, less television watching, and more sleep. No differences were found in physical health measures. In gender stratified analyses differences in life satisfaction by education remained among both genders, but specific gender differences emerged for physical health measures. That is, women without a secondary education had lower fitness, more somatic complaints and higher diastolic blood pressure, as well as marginally higher waistcircumference compared with women with a secondary education. No differences were seen in men, aside from a trend towards more somatic complaints $(p=$ 0.07). Regarding health-behaviors, men without a secondary education reported more time spent watching television, while women without a secondary education reported less sports participation and worse sleep. Notably, $70 \%$ of women with elementary education never/rarely exercised, compared with $35 \%$ of women with a secondary education $(p=0.023)$. Moreover, $46 \%$ of women with elementary education versus $5 \%$ of women with a secondary education reported seldom getting enough sleep $(p<0.001)$, with $15 \%$ vs. $63 \%$ of these women (respectively) stating they slept $\geq 7 \mathrm{~h}$ each night ( $p$ $<0.002$ ). Elementary educated women were also more likely to have child-raising responsibilities, as $46 \%$ of them reported having children as compared with $13 \%$ of women with a secondary education $(p<0.01)$. Lastly, occupational status differed by education status across the whole sample, with a higher prevalence of unemployment and working full-time among elementary educated participants, and a higher prevalence of current studying and working part-time among participants with a secondary education.

\section{Influence of adolescents' physical health and health-behaviors on dropout odds}

In logistic regression analyses across the sample (see Table 3) somatic complaints, smoking, alcohol drinking and time spent watching television were associated with higher odds of dropout, while self-esteem and mothers' education were associated with lower odds of dropout from secondary education. No association emerged however between objective physical health measures, consisting of fitness, physical activity and body composition measures, and odds of dropout.

In total, three regression models (see Table 3) were conducted which included adjustments for possible confounders (i.e. gender in model 1, parental education and neighborhood characteristics in model 2 , and psychological factors (self-esteem and depression) in model 3). In these analyses, somatic complaints remained a significant predictor associated with higher odds of dropout across all models (with OR 1.09, 95 \% CI:1.02-1.18 in model 1 , and nearly identical ORs in models 2 and 3). In the realm of health-behaviors, smoking at age 15 was associated with fourfold higher odds of dropout from secondary education, independent of gender (OR 3.67, $95 \%$ CI:1.50-9.00), or parental education and neighborhood characteristics (OR 3.64, 95 \% CI:1.42-9.33), and threefold odds of dropout after adjustment for psychological 
Table 1 Demographics and covariates at baseline for the whole sample and across gender

\begin{tabular}{|c|c|c|c|c|}
\hline Demographics and covariates at baseline & Whole sample $N=201$ & Girls $N=92$ & Boys $N=109$ & $p$-value \\
\hline Age (baseline) M (SD) & $15.3(0.3)$ & $15.3(0.3)$ & $15.4(0.3)$ & 0.017 \\
\hline \multicolumn{5}{|l|}{ Education of participants } \\
\hline Elementary education & $19 \%(38)$ & $14 \%(13)$ & $23 \%(25)$ & 0.11 \\
\hline Vocational studies & $13 \%(27)$ & $5 \%(5)$ & $20 \%(22)$ & 0.002 \\
\hline Matriculation examination & $49 \%(99)$ & $61 \%(56)$ & $39 \%(43)$ & 0.002 \\
\hline University degree & $12 \%(24)$ & $12 \%(11)$ & $12 \%(13)$ & 1.00 \\
\hline Other & $7 \%(13)$ & $8 \%(7)$ & $6 \%(6)$ & 0.55 \\
\hline \multicolumn{5}{|l|}{ Mother's education status } \\
\hline Elementary education & $23 \%(45)$ & $21 \%(19)$ & $24 \%(26)$ & \\
\hline Secondary education & $37 \%(74)$ & $38 \%(35)$ & $36 \%(39)$ & $0.86^{*}$ \\
\hline University degree & $40 \%(80)$ & $41 \%(37)$ & $40 \%(43)$ & \\
\hline \multicolumn{5}{|l|}{ Father's education status } \\
\hline Elementary education & $19 \%(37)$ & $20 \%(18)$ & $18 \%(19)$ & $0.74^{*}$ \\
\hline Secondary education & $51 \%(101)$ & $50 \%(45)$ & $52 \%(56)$ & \\
\hline University degree & $30 \%(61)$ & $30 \%(28)$ & $30 \%(30)$ & \\
\hline \multicolumn{5}{|l|}{ Neighborhood characteristics } \\
\hline Capital area & $50 \%(100)$ & $50 \%(46)$ & $49 \%(54)$ & 0.95 \\
\hline Urban/ Rural & $50 \%(101)$ & $50 \%(46)$ & $51 \%(55)$ & \\
\hline \multicolumn{5}{|l|}{ Psychological factors } \\
\hline Self-esteem (baseline) M (SD) & $21.7(5.6)$ & $21.0(5.7)$ & $22.3(5.5)$ & 0.12 \\
\hline Depression (baseline) M (SD) & $15.5(6.0)$ & $16.8(7.2)$ & $14.4(4.6)$ & 0.008 \\
\hline
\end{tabular}

factors (OR 2.90, 95 \% CI:1.14-7.40). Alcohol drinking was likewise associated with approximately 2.5 higher odds of dropout, independent of gender $(2.57,95 \%$ CI:1.15-5.75) and psychological factors (2.36, $95 \%$ CI:1.03-5.40), but the association lost significance when parental education status and neighborhood characteristics was taken into account. Time spent watching television also emerged as an independent predictor, where a one unit increase in television watching was linked with 1.3 higher odds of dropout in young adulthood across all models (e.g. OR 1.27, 95 \% CI:1.03-1.56 in Model 1).

Among covariates, self-esteem was associated with lower odds of dropout at age 23, independent of other covariates in models 1-3 (e.g. OR 0.91, 95 \% CI: 0.85-0.98 for Model 1). Finally, mother's higher education status at follow-up was also strongly associated with lower dropout odds, independent of gender (OR 0.54, 95 \% CI: 0.34$0.88)$, father's education and neighborhood characteristics (OR 0.57, 95 \% CI: 0.33-0.98), and psychological factors (OR 0.53, 95 \% CI: 0.31-0.91). No association was found however with fathers' education and neighborhood characteristics (see Table 3).

\section{Discussion}

This prospective study spanning eight years reports on the interrelationship between adolescent's health and educational attainment in young adulthood, focusing on how physical health and health-behaviors of youths affect their odds of dropout from secondary education. A completion of secondary education in young adulthood was associated with less somatic complaints, more sports participation, less television watching, poorer sleep, higher life satisfaction, and occupational status. This is consistent with the well-established educational/ social gradient in health, where lower education has consistently been associated with poor health, including negative health-behaviors, morbidity and mortality [9]. These findings strongly suggest that an educational health gradient does exist in Iceland, but according to a report of the OECD it is only very recently that Icelandic authorities have started acknowledging the existence of health inequalities among its inhabitants [30]. Recent data from Sweden have likewise indicated a presence of social inequalities in mental health of adolescents in a country with small social differences [31]. In the current 
Table 2 Differences in physical health, health - behaviors and psychological factors at follow-up by education status

\begin{tabular}{|c|c|c|c|c|c|c|}
\hline & \multicolumn{2}{|l|}{ Total sample } & \multicolumn{2}{|l|}{ Girls } & \multicolumn{2}{|l|}{ Boys } \\
\hline & $\begin{array}{l}\text { Elementary } \\
\text { education }(n=38)\end{array}$ & $\begin{array}{l}\text { Secondary } \\
\text { education }(n=150)\end{array}$ & $\begin{array}{l}\text { Elementary } \\
\text { education }(n=13)\end{array}$ & $\begin{array}{l}\text { Secondary } \\
\text { education }(n=72)\end{array}$ & $\begin{array}{l}\text { Elementary } \\
\text { education }(n=25)\end{array}$ & $\begin{array}{l}\text { Secondary } \\
\text { education }(n=78)\end{array}$ \\
\hline \multicolumn{7}{|l|}{ Physical health } \\
\hline Fitness (W/kg) & $2.7(0.7)$ & $2.8(0.6)$ & $2.0(0.5)^{* *}$ & $2.5(0.5)^{* *}$ & $2.9(0.5)$ & $3.0(0.5)$ \\
\hline Physical activity (counts/min) & $559(208)$ & $555(186)$ & $492(82)$ & $492(122)$ & $581(236)$ & $615(216)$ \\
\hline Body mass index $\left(\mathrm{kg} / \mathrm{m}^{2}\right)$ & $24.6(4.5)$ & $24.4(3.8)$ & $24.7(4.8)$ & $23.6(3.3)$ & $24.6(4.2)$ & $25.1(4.0)$ \\
\hline Waist circumference $(\mathrm{cm})$ & $79.4(10.8)$ & $78.4(11.0)$ & $76.8(11.1)$ & $72.1(7.2)$ & $80.8(9.3)$ & $84.2(10.8)$ \\
\hline Skinfold thickness $(\mathrm{cm})$ & $114.6(58.1)$ & $120.0(50.3)$ & $150.1(70.6)$ & $130.6(48.3)$ & $94.1(37.9)$ & $110.2(50.4)$ \\
\hline Somatic complaints & $15.3(7.4)^{* *}$ & $13.1(4.3)^{* *}$ & $16.5(5.6)^{*}$ & $13.5(4.4)^{*}$ & $14.7(4.9)$ & $12.8(4.1)$ \\
\hline $\begin{array}{l}\text { Systolic blood } \\
\text { pressure }(\mathrm{mm} / \mathrm{Hg})\end{array}$ & $121(11.9)$ & $117.3(11.4)$ & $114.4(10.3)$ & $111.1(8.6)$ & $124.7(11.2)$ & $122.9(10.8)$ \\
\hline $\begin{array}{l}\text { Diastolic blood } \\
\text { pressure }(\mathrm{mm} / \mathrm{Hg})\end{array}$ & $74.0(7.1)$ & $72.5(6.0)$ & $76.6(8.9)^{*}$ & $71.5(6.6)^{*}$ & $72.7(5.7)$ & $73.3(5.7)$ \\
\hline \multicolumn{7}{|l|}{ Health - behaviors } \\
\hline Smoking & $5 \%(2)$ & $3 \%(4)$ & $8 \%(1)$ & $1 \%(1)$ & $4 \%(1)$ & $4 \%(3)$ \\
\hline Alcohol drinking & $82 \%(31)$ & $86 \%(127)$ & $92 \%(12)$ & $86 \%(62)$ & $76 \%$ (19) & $87 \%(65)$ \\
\hline \multicolumn{7}{|c|}{ Moderate/vigorous physical activity } \\
\hline Never/rarely & $19 \%(6)$ & $8 \%(11)$ & $30 \%(3)$ & $9 \%(6)$ & $14 \%(3)$ & $7 \%(5)$ \\
\hline 1-3 times a week & $22 \%(7)$ & $33 \%(47)$ & $30 \%(3)$ & $39 \%(27)$ & $18 \%(4)$ & $28 \%(20)$ \\
\hline$\geq 4$ times a week & $59 \%(19)$ & $59 \%(83)$ & $40 \%(4)$ & $52 \%(36)$ & $68 \%(15)$ & $65 \%(47)$ \\
\hline \multicolumn{7}{|c|}{ Physical activity with a sports club } \\
\hline Never/rarely & $40 \%(13)$ & $31 \%(44)$ & $70 \%(7)^{*}$ & $35 \%(24)^{*}$ & $27 \%(6)$ & $28 \%(20)$ \\
\hline 1-3 times a week & $13 \%(4)$ & $23 \%(33)$ & $20 \%(2)^{*}$ & $26 \%(18)^{*}$ & $9 \%(2)$ & $21 \%(15)$ \\
\hline$\geq 4$ times a week & $47 \%(15)$ & $45 \%(64)$ & $10 \%(1)^{*}$ & $39 \%(27)^{*}$ & $64 \%(14)$ & $51 \%(37)$ \\
\hline $\begin{array}{l}\text { Watch television }>2 \mathrm{~h} \\
\text { on weeknights }\end{array}$ & $47 \%(18)^{*}$ & $27 \%(40)^{*}$ & $39 \%(5)$ & $26 \%(19)$ & $52 \%(13)^{*}$ & $27 \%(21)^{*}$ \\
\hline Seldom get enough sleep & $27 \%(9)^{* *}$ & $6 \%(9)^{* *}$ & $46 \%(6)^{* *}$ & $5 \%(4)^{* *}$ & $12 \%(3)$ & $6 \%(5)$ \\
\hline Sleep $\geq 7 \mathrm{~h}$ each night & $32 \%(12)^{* *}$ & $55 \%(83)^{* *}$ & $15 \%(2)^{* *}$ & $63 \%(45)^{* *}$ & $40 \%(10)$ & $49 \%(38)$ \\
\hline \multicolumn{7}{|l|}{ Psychological factors } \\
\hline Self-esteem & $21.5(6.4)$ & $23.4(5.4)$ & $21.5(6.1)$ & $23.9(5.0)$ & $21.6(6.6)$ & $22.9(5.8)$ \\
\hline Depression & $16.8(7.4)$ & $14.8(4.9)$ & $18.2(7.9)$ & $15.4(5.5)$ & $16.0(7.1)$ & $14.2(4.3)$ \\
\hline Life satisfaction & $22.8(6.5)^{* *}$ & $26.3(4.9)^{* *}$ & $23.5(4.8)^{*}$ & $27.1(4.8)^{*}$ & $21.3(7.3)^{*}$ & $25.5(4.8)^{*}$ \\
\hline Social support & $17.3(2.9)$ & $18.1(2.3)$ & $36.4(4.4)$ & $36.3(3.6)$ & $31.8(5.7)$ & $33.7(4.6)$ \\
\hline \multicolumn{7}{|l|}{ Demographics } \\
\hline Child-rearing responsibilities & $26 \%(10)$ & $14 \%(21)$ & $46 \%(6)^{* *}$ & $13 \%(9)^{* *}$ & $16 \%(4)$ & $15 \%(12)$ \\
\hline Working full-time & $47 \%(18)^{* *}$ & $21 \%(32)^{* *}$ & $23 \%(3)$ & $17 \%(12)$ & $60 \%(15)^{* *}$ & $26 \%(20)^{* *}$ \\
\hline Unemployed & $13 \%(5)^{* *}$ & $1 \%(2)^{* *}$ & $15 \%(2)^{*}$ & $1 \%(1)^{*}$ & $12 \%(3)^{*}$ & $1 \%(1)^{*}$ \\
\hline Working part-time & $18 \%(7)^{* *}$ & $41 \%(62)^{* *}$ & $23 \%(3)$ & $47 \%(34)$ & $16 \%(4)$ & $36 \%(28)$ \\
\hline Studying & $42 \%(16)^{* *}$ & $76 \%(114)^{* *}$ & $46 \%(6)^{* *}$ & $82 \%(59)^{* *}$ & $40 \%(10)^{* *}$ & $71 \%(55)^{* *}$ \\
\hline
\end{tabular}

Numbers in the table represent: Mean (Standard Deviation) for continuous variables (all Physical health and Psychological factors variables) and \% (number of participants) for categorical variables (all Health -behavior and Demographic variables)

${ }^{*} p<0.05$; ${ }^{* *} p<0.01$

study, girls especially displayed substantial health benefits from gaining a secondary education, as compared with boys. Of specific interest were the low fitness, poorer bodily health, higher blood-pressure, lack of sleep, and more child-rearing responsibilities among women without a secondary education. Perhaps secondary education is more vital for the well-being of Icelandic women as they may be less likely than men to be 
Table 3 Association of physical health, health-behaviors and covariates with dropout odds from secondary education

\begin{tabular}{|c|c|c|c|c|c|c|}
\hline \multirow[b]{3}{*}{ Baseline measures } & \multirow{2}{*}{\multicolumn{2}{|c|}{$\begin{array}{l}\text { Model } 1^{\mathrm{a}} \\
\text { Adjusted for gender }\end{array}$}} & \multirow{2}{*}{\multicolumn{2}{|c|}{$\begin{array}{l}\text { Model } 2^{\mathrm{b}} \\
\text { Adjusted for gender, parental education } \\
\text { and neighborhood characteristics }\end{array}$}} & \multirow{2}{*}{\multicolumn{2}{|c|}{$\begin{array}{l}\text { Model } 3^{c} \\
\text { Adjusted for gender and } \\
\text { psychological factors }\end{array}$}} \\
\hline & & & & & & \\
\hline & $\bar{N}$ & OR $(95 \% \mathrm{Cl})$ & $\bar{N}$ & OR $(95 \% \mathrm{Cl})$ & $\bar{N}$ & OR $(95 \% \mathrm{Cl})$ \\
\hline \multicolumn{7}{|l|}{ Physical health } \\
\hline Fitness (W/kg) & 114 & $0.68(0.33-1.41)$ & 110 & $0.55(0.25-1.19)$ & 107 & $0.84(0.34-2.09)$ \\
\hline Physical activity (counts/min) & 80 & $1.00(1.00-1.00)$ & 77 & $1.00(0.99-1.00)$ & 76 & $1.00(1.00-1.00)$ \\
\hline Body mass index (kg/m2) & 188 & $1.05(0.93-1.18)$ & 184 & $1.07(0.94-1.20)$ & 172 & $1.10(0.94-1.27)$ \\
\hline Waist circumference $(\mathrm{cm})$ & 188 & $1.02(0.98-1.06)$ & 184 & $1.03(0.98-1.07)$ & 172 & $1.03(0.97-1.08)$ \\
\hline Skinfold thickness (mm) & 188 & $1.01(0.99-1.02)$ & 184 & $1.01(0.99-1.02)$ & 172 & $1.00(0.99-1.02)$ \\
\hline Somatic complaints & 170 & $1.09(1.02-1.18)^{*}$ & 167 & $1.09(1.01-1.18)^{*}$ & 168 & $1.10(1.00-1.20)^{*}$ \\
\hline \multicolumn{7}{|l|}{ Health - behaviors } \\
\hline Smoking & 173 & $3.67(1.50-9.00)^{* *}$ & 170 & $3.64(1.42-9.33)^{* *}$ & 171 & $2.90(1.14-7.40)^{*}$ \\
\hline Alcohol drinking & 163 & $2.57(1.15-5.75)^{*}$ & 160 & $2.14(0.93-4.93)$ & 161 & $2.36(1.03-5.40)^{*}$ \\
\hline Time spent watching television & 173 & $1.27(1.03-1.56)^{*}$ & 170 & $1.28(1.03-1.60)^{*}$ & 171 & $1.25(1.01-1.55)^{*}$ \\
\hline Frequency of sports participation & 173 & $0.84(0.54-1.30)$ & 170 & $0.82(0.52-1.30)$ & 171 & $0.94(0.59-1.49)$ \\
\hline Frequency of moderate/vigorous physical activity & 173 & $0.74(0.42-1.92)$ & 170 & $0.81(0.46-1.45)$ & 171 & $0.87(0.49-1.57)$ \\
\hline \multicolumn{7}{|l|}{ Covariates } \\
\hline Gender (female) & 188 & $1.78(0.85-3.73)$ & 184 & $1.51(0.70-3.27)$ & 172 & $2.42(1.02-5.75)^{*}$ \\
\hline Mothers higher education & 186 & $0.54(0.34-0.88)^{*}$ & 184 & $0.57(0.33-0.98)^{* d}$ & 170 & $0.53(0.31-0.91)^{*}$ \\
\hline Fathers higher education & 186 & $0.70(0.42-1.19)$ & 184 & $0.86(0.47-1.58)^{\mathrm{e}}$ & 171 & $0.78(0.43-1.39)$ \\
\hline Neighborhood characteristics (rural/urban) & 188 & $1.10(0.54-2.26)$ & 184 & $0.80(0.37-1.74)^{f}$ & 172 & $1.15(0.52-2.56)$ \\
\hline Self-esteem & 174 & $0.91(0.85-0.98)^{*}$ & 171 & $0.90(0.84-0.97)^{* *}$ & 172 & $0.92(0.85-0.99)^{* 9}$ \\
\hline Depression & 172 & $1.06(0.99-1.13)$ & 169 & $1.06(1.00-1.14)$ & 172 & $1.02(0.95-1.10)^{h}$ \\
\hline
\end{tabular}

${ }^{*} p<0.05 ;{ }^{* *} p<0.01 .{ }^{a}$ Model adjusted for gender; ${ }^{b}$ Model adjusted for gender, parental education and neighborhood characteristics; ${ }^{c}$ Model adjusted for gender, self-esteem and depression; ${ }^{\mathrm{d}}$ Only adjusted for fathers education status and neighborhood characteristics; ${ }^{\mathrm{e}}$ Only adjusted for mothers education status and neighborhood characteristics;

fOnly adjusted for mothers and fathers education status; ${ }^{9}$ Only adjusted for depression at age $15 ;{ }^{\text {h }}$ Only adjusted for self-esteem at age 15

able to secure a well-paying job without an educational degree. Moreover, it can be hypothesized that getting pregnant at a young age may hinder these women in completing their secondary education, and that more support is needed for young mothers in Iceland.

Regarding the prognostic importance of physical health for education outcomes, somatic complaints, negative health - behaviors, self-esteem and mothers education status emerged as significant risk factors for dropout from secondary education. Somatic complaints were linked with higher odds of dropout from secondary education, independent of both psychological factors and the socioeconomic status of students. This concurs with recent large scale studies which have linked selfreported poor health with lower odds of completing high school independent of socioeconomic status $[8,32]$. No association emerged however between objective measures of physical activity or fitness with dropout, contrary to a large longitudinal study which found a relationship between academic achievement and objective measures of physical activity [33]. This may be due to lower power based on the smaller sample in the current study. Among health-behaviors, smoking and more television watching predicted higher odds of dropout from secondary education regardless of all covariates, while alcohol drinking predicted dropout independent of gender and psychological factors, but not when parental education was taken into account. According to this, parental influences may reduce the effects of adolescent drinking on lower educational attainment, but review findings have suggested that negative health-behaviors have a more complex relationship with academic achievement, and may be mediated by socioeconomic status and psychosocial problems [34]. Indeed, data from Norway, Sweden, Denmark, Finland, and the United Kingdom have found social inequalities in daily smoking among adolescents, and that this association was partially mediated by academic achievement [35].

Importantly, mother's higher education emerged as a protective factor against dropout, but no association was found with father's education or neighborhood characteristics. It is well established that parental education 
denotes socio-economic status and is an important predictor of children's educational outcomes [14]. Contrary to these findings, the Icelandic Ministry of Education, Science and Culture has recently claimed that socioeconomic status has a relatively little impact on the education achievement of Icelandic students [5]. A higher level of parental education is thought to contribute to better academic achievement via a more supportive home learning environment, encouragement for higher achievement and psychological support [36]. It is unclear why no association was found with fathers' higher education, but very few studies have investigated the individual contribution of mothers and fathers on the educational outcomes of their children [37]. One American study has though marked fathers education as more important for boys advancement to higher education, as compared with girls [38]. It may be that the supporting role provided by educated mothers is more vital for the educational attainment of Icelandic students. The unexpected lack of association between neighborhood characteristics and dropout risk possibly results from low power due to the relatively low number of participants in the current study. Published numbers from the Statistics Iceland for all students starting secondary school in Iceland in the year 2004 indicate that $25 \%$ of students living in the Reykjavik capital area dropout from secondary education within four years compared with $32 \%$ of students living in urban or rural areas. Likewise, based on their numbers around $49 \%$ of students in the capital area complete their secondary education within the allocated four years compared with $37 \%$ of students living in the countryside [39]. Yet, a report from the OECD states that the socio-economic background of Icelandic students has less of an effect on their academic achievement compared to other OECD countries [4]. Hence, it seems that Icelandic authorities and further research projects need to ascertain to what extent socio-economic inequalities in health and education exist within the Icelandic society.

The strength of this study resides in the longitudinal design, objective measures of physical health, and taking into account the effects of psychological and socioeconomic status. The main limitations of the current study include the presence of some participant dropout from baseline to follow-up, which may increase risk of selection bias. Of note, non-responders may represent a group with higher dropout rates from secondary education, and this possible selection bias might thus yield attenuated associations in the study findings [8]. Secondly, objective measures of fitness and physical activity were only conducted among half of the sample at baseline, which reduces statistical power for analyses including those variables. Finally, measurements of education completion were based on self-report, limiting the robustness of the measurements.

\section{Conclusions}

This study yields important information regarding diverse health-benefits associated with obtaining a secondary education degree in a European country, and how physical health and health-behaviors of adolescents affect their likelihood of gaining such a degree. The findings suggest that somatic complaints and negative healthbehaviors among adolescents increase their chances of dropout from secondary education, and that securing a secondary education degree yields numerous healthbenefits, specifically among women. The potential pathways behind this association are believed to range across many health factors. Poor health in adolescents may for instance lead to lower levels of schooling by means of more days missed at school [40], and lower capability to learn in school [32]. Of specific concern in this regard are the lower levels of fitness and physical activity seen among adolescents today [41], which can result in poorer health status accompanied by more somatic complaints, headaches, and bodily discomfort, that can impede students capacity and productivity in school. In line with this are study findings which have linked migraine headaches with lower educational attainment [42] and frequent primary care visits with more days absent from school [43] and higher odds of dropout [40]. Accordingly, it seems poor physical health during adolescence can have wide - ranging consequences for the future prospects of youths [32]. Leading educational organizations and policy makers in the United States are increasingly recognizing the important role schools play for addressing health issues among youths [44], and this view should be incorporated into public health policies worldwide.

\section{Abbreviations}

BMI: Body mass index; OECD: Organization for Economic Co-operation and Development; OR: Odds ratio; SCL-90: Symptom checklist 90.

\section{Competing interest}

The author(s) declare that they have no conflict of interest.

\section{Authors' contributions}

ES designed the overall concept of the manuscript, conducted statistical analyses and interpretation of data, and wrote the first draft of the manuscript. SAA and TS participated in the design of the study and conducted data acquisition, as well as providing feedback and revision of the manuscript for important intellectual content. EJ was involved in designing the concept of the manuscript, planning analyses and drafting of the manuscript. All authors have given their final approval of the manuscript, and agree to be accountable for all aspects of accuracy and integrity of the work. No author received honorarium, grant, of other form of payment to produce the manuscript.

\section{Acknowledgements}

This work was supported by the University of Iceland's Centennial Fund (granted to EJ, Dr. Steinunn Gestsdóttir and Dr. Ingólfur Asgeir Jóhannesson), a grant from the Public Health Fund of the Icelandic Directorate of Health to ES, and by a grant from the Icelandic Centre of Research to SA, TS, and EJ (nr:040418021 and 011069023). The results of this paper have been presented in an oral presentation at Menntakvika, an annual congress organized by the School of Education, University of Iceland focusing on educational research and development. 


\section{Author details}

${ }^{1}$ School of Education, University of Iceland, Stakkahlíð, 105 Reykjavík, Iceland. ${ }^{2}$ Center for Sport and Health Sciences, University of Iceland, Lindarbraut 4, 840 Laugarvatn, Iceland. ${ }^{3}$ Research Centre of Movement Science, School of Health Sciences, University of Iceland, Stapi v/Hringbraut, 101 Reykjavík, Iceland. 'Landspitali-University Hospital, Eiríksgötu 5, 101, Reykjavík, Iceland.

\section{Received: 19 January 2015 Accepted: 12 November 2015} Published online: 24 November 2015

\section{References}

1. UNESCO. Chapter 5: Secondary education - paving the way to work. Youth and skills: Putting Education to Work. In: EFA Global Monitoring Report. Paris: UNESCO; 2012. p. 226-53.

2. Tyler JH, Lofstrom M. Finishing high school: alternative pathways and dropout recovery. Future Child. 2009;19(1):77-103.

3. Blondal KS, Jonasson JT, Tannhauser AC. Dropout in a small society: is the Icelandic case somehow different? In: Lamb S, Markussen E, Teese R, Sandberg N, Polesel J, editors. School Dropout and Completion: International Comparative Studies in Theory and Policy. London: Springer; 2011. p. 233-51.

4. OECD. Towards a strategy to prevent dropout in Iceland, Preventing dropout in upper secondary schools in Iceland. 2012. http://www.oecd.org/ iceland/49451462.pdf. Accessed 7 march 2014.

5. Ministry of Education Science and Culture. [White book about reforms in education]. 2014. http://www.menntamalaraduneyti.is/media/frettir/Hvitbik_ Umbaetur_i_menntun.pdf. Accessed 3 Nov 2014.

6. Birgisdóttir K. [Drop-out in secondary education: Spring 2013]. 2013. Ministry of Education, Science and Culture. http://brunnur.stjr.is/mrn/utgafuskra/ utgafa.nsf/xsp/.ibmmodres/domino/OpenAttachment/mrn/utgafuskra/ utgafa.nsf/B249B4FD1491ED2700257C22004C69A5/Attachment/brotthv_ frsk_2013.pdf Assessed 19 Aug 2014.

7. Winding TN, Nohr EA, Labriola M, Biering K, Andersen JH. Personal predictors of educational attainment after compulsory school: influence of measures of vulnerability, health, and school performance. Scand J Public Health. 2013:41(1):92-101. doi:10.1177/1403494812467713.

8. De Ridder KA, Pape K, Johnsen R, Holmen TL, Westin S, Bjorngaard JH. Adolescent health and high school dropout: a prospective cohort study of 9000 Norwegian adolescents (the young-HUNT). PLoS One. 2013;8(9): e74954. doi:10.1371/journal.pone.0074954.

9. Mackenbach JP, Stirbu I, Roskam A-JR, Schaap MM, Menvielle G, Leinsalu M, et al. Socioeconomic inequalities in health in 22 European Countries. N England J Med. 2008;358(23):2468-81. doi:10.1056/NEJMsa0707519.

10. Suhrcke $M$, de Paz Nieves $C$. The impact of health and health behaviors on educational outcomes in high-income countries: A review of the evidence. Copenhagen, WHO Regional Office for Europe; 2011

11. Ansari WE, Stock C. Is the health and wellbeing of university studetns associated with their academic performance? Cross sectional findings from the United Kingdom. Int J Environ Res Public Health. 2010;7:509-27.

12. Cutler DM, Lleras-Muney A. Education and health: evaluating theories and evidence. In: Schoeni RF, House JS, Kaplan GA, Pollack H, editors. Making Americans Healthier: Social and Economic Polisy as Health Policy. New York: Russel Sage Foundation; 2008.

13. Koivusilta LK, Nupponen $H$, Rimpelä AH. Adolescent physical activity predicts high education and socio-economic position in adulthood. Eur J Public Health. 2011:22(2):203-9. doi:10.1093/eurpub/ckr037.

14. Dubow EF, Boxer P, Huesmann LR. Long-term Effects of Parents' Education on Children's Educational and Occupational Success: Mediation by Family Interactions, Child Aggression, and Teenage Aspirations. Merrill Palmer Q (Wayne State Univ Press). 2009;55(3):224-49. doi:10.1353/mpq.0.0030.

15. Halldórsson M, Cavelaars AEJM, Kunst AE, Mackenbach JP. Socioeconomic differences in health and well-being of children and adolescents in Iceland. Scand J Public Health. 1999;27(1):43-7. doi:10.1177/14034948990270011501.

16. Nielsen L, Damsgaard MT, Meilstrup C, Due P, Madsen KR, Koushede V, et al. Socioeconomic differences in emotional symptoms among adolescents in the Nordic countries: Recommendations on how to present inequality. Scand J Public Health. 2015:43(1):83-90. doi:10.1177/1403494814557885.

17. Bernburg JG, Thorlindsson T, Sigfusdottir ID. The neighborhood effects of disrupted family processes on adolescent substance use. Soc Sci Med. 2009; 69(1):129-37. http://dx.doi.org/10.1016/j.socscimed.2009.04.025.
18. Ministry of Education Science and Culture. The Educational System of Iceland. Reykjavik: Ministry of Education Science and Culture; 2002.

19. Riddoch CJ, Bo Andersen L, Wedderkopp N, Harro M, Klasson-Heggebø L, Sardinha LB, et al. Physical activity levels and patterns of 9- and 15-yr-old European children. Med Sci Sports Exerc. 2004;36(1):86-92.

20. Arngrimsson SA, Sveinsson T, Johannsson E. Peak oxygen uptake in children: evaluation of an older prediction method and development of a new one. Pediatr Exerc Sci. 2008;20(1):62-73.

21. Wedderkopp N, Froberg K, Hansen HS, Andersen LB. Secular trends in physical fitness and obesity in Danish 9-year-old girls and boys: Odense School Child Study and Danish substudy of the European Youth Heart Study. Scand J Med Sci Sports. 2004;14(3):150-5. doi:10.1046/j.1600-0838. 2003.00365.x.

22. Ekelund U, Anderssen SA, Froberg K, Sardinha LB, Andersen LB, Brage S. Independent associations of physical activity and cardiorespiratory fitness with metabolic risk factors in children: the European youth heart study. Diabetologia. 2007:50(9):1832-40. doi:10.1007/s00125-007-0762-5.

23. Ekelund U, Sjostrom M, Yngve A, Poortvliet E, Nilsson A, Froberg K, et al. Physical activity assessed by activity monitor and doubly labeled water in children. Med Sci Sports Exerc. 2001;33(2):275-81.

24. Derogatis LR, Lipman RS, Rickels K, Uhlenhuth EH, Covi L. The Hopkins Symptom Checklist (HSCL): a self-report symptom inventory. Behav Sci. 1974;19(1):1-15.

25. Rosenberg M. Society and the Adolescent Self-image. Princeton, N.J.: Princeton University Press; 1965.

26. Sigurjónsdóttir ED. Psychometric Properties of the Icelandic version of the Rosenberg Self-Esteem Scale. Reykjavík: University of Iceland; 2012.

27. Diener E, Emmons RA, Larsen RJ, Griffin S. The satisfaction with life scale. J Pers Assess. 1985;49(1):71-5. doi:10.1207/s15327752jpa4901_13.

28. Zimet GD, Dahlem NW, Zimet SG, Farley GK. The multidimensional scale of perceived social support. J Pers Assess. 1988:52(1):30-41.

29. Zimet GD, Powell SS, Farley GK, Werkman S, Berkoff KA. Psychometric characteristics of the multidimensional scale of perceived social support. J Pers Assess. 1990;55(3-4):610-7. doi:10.1080/00223891.1990.9674095.

30. European-Union. Health inequalities in the EU: Final report of a consortium. Consortium lead: Sir Michael Marmot. 2013. http://www.thehealthwell.info/ node/681223: Assessed 29 september 2014.

31. Wirback T, Moller J, Larsson J-O, Galanti M, Engstrom K. Social factors in childhood and risk of depressive symptoms among adolescents - a longitudinal study in Stockholm, Sweden. Int J Equity Health. 2014;13(1):96.

32. Jackson MI. Understanding links between adolescent health ad educational attainment. Demography. 2009;46(4):671-94.

33. Booth JN, Leary SD, Joinson C, Ness AR, Tomporowski PD, Boyle JM, et al. Associations between objectively measured physical activity and academic attainment in adolescents from a UK cohort. Br J Sports Med. 2014;48(3): 265-70. doi:10.1136/bjsports-2013-092334.

34. Busch V, Loyen A, Lodder M, Schrijvers AJP, van Yperen TA, de Leeuw JRJ. The effects of adolescent health-related behavior on academic performance: a systematic review of the longitudinal evidence. Rev Educ Res. 2014:84(2):245-74. doi:10.3102/0034654313518441.

35. Schnohr C, Kreiner S, Rasmussen M, Due P, Diderichsen F. School-related mediators in social inequalities in smoking: a comparative cross-sectional study of 20,399 adolescents. Int J Equity Health. 2009;8(1):17.

36. Kantomaa MT, Tammelin TH, Demakakos P, Ebeling HE, Taanila AM. Physical activity, emotional and behavioural problems, maternal education and self-reported educational performance of adolescents. Health Educ Res. 2009;25(2):368-79. doi:10.1093/her/cyp048.

37. Flouri E, Buchanan A. Early father's and mother's involvement and child's later educational outcomes. Brit J Educ Psychol. 2004;74(2):141-53.

38. Buchmann C, DiPrete TA. The growing female advantage in college completion: the role of family background and academic achievement. Am Sociol Rev. 2006;71(4):515-41. doi:10.1177/000312240607100401.

39. Statistics_Iceland. More dropout at the upper secondary level outside of the capital region. 2014. http://www.hagstofa.is/en/publications/newsarchive/ education/more-dropout-at-the-upper-secondary-level-outside-of-thecapital-region/. Accessed November 19, 2015.

40. Homlong L, Rosvold EO, Haavet OR. Can use of healthcare services among 1516-year-olds predict an increased level of high school dropout? A longitudinal community study. BMJ Open. 2013. 3(9). doi:10.1136/bmjopen-2013-003125.

41. Dumith SC, Gigante DP, Domingues MR, Kohl HW. Physical activity change during adolescence: a systematic review and a pooled analysis. Int J Epidemiol. 2011;40(3):685-98. 
42. Rees DI, Sabia JJ. The effect of migraine headache on educational attainment. J Hum Resour. 2011;46(2):317-32.

43. Vila M, Kramer T, Obiols J, Garralda ME. Adolescents who are frequent attenders to primary care: contribution of psychosocial factors. Soc Psych Psych Epid. 2012;47(2):323-9. doi:10.1007/s00127-010-0326-8.

44. Basch CE. Healthier students are better learners: a missing link in school reforms to close the achievement gap. J School Health. 2011;81(10):593-8. doi:10.1111/j.1746-1561.2011.00632.x.

Submit your next manuscript to BioMed Central and take full advantage of:

- Convenient online submission

- Thorough peer review

- No space constraints or color figure charges

- Immediate publication on acceptance

- Inclusion in PubMed, CAS, Scopus and Google Scholar

- Research which is freely available for redistribution 